\title{
Microarray analysis of differentially expressed long non-coding RNAs in daidzein-treated lung cancer cells
}

\author{
LAIFANG LI ${ }^{1,2}$, JUN LIU ${ }^{2}$, XIAOBO WANG ${ }^{1,2}$, XIAOWEI XIONG ${ }^{1}$, SHAOXIN HUANG $^{2}$ and XIN WANG ${ }^{2}$ \\ ${ }^{1}$ Jiangxi Provincial Key Laboratory of Preventive Medicine, School of Public Health, Nanchang \\ University, Nanchang, Jiangxi 330006; ${ }^{2}$ Department of Social Medicine and Public Health, \\ School of Basic Medicine, Jiujiang University, Jiujiang, Jiangxi 332005, P.R. China
}

Received July 8, 2020; Accepted January 26, 2021

DOI: $10.3892 / \mathrm{ol} .2021 .13050$

\begin{abstract}
Daidzein has been found to significantly inhibit the proliferation of lung cancer cells, while its potential molecular mechanisms remain unclear. To determine the molecular mechanism of daidzein on lung cancer cells, the Capital Bio Technology Human long non-coding (lnc) RNA Array v4, $4 \times 180 \mathrm{~K}$ chip was used to detect the gene expression profiles of 40,000 lncRNAs and 34,000 mRNAs in a human cancer cell line. Reverse transcription-quantitative (RT-q) PCR analysis was performed to detect the expression levels of target lncRNA and mRNAs in the H1299 cells treated with and without daidzein, using the lncRNA and mRNA gene chip. Bioinformatics analysis was performed to determine the differentially expressed genes from the results of the chip assays. There were 119 and 40 differentially expressed lncRNAs and mRNAs, respectively, that had a 2-fold change in expression level. A total of eight lncRNAs were upregulated in the H1299 lung cancer cells, while 111 lncRNAs were downregulated. Furthermore, five mRNAs were upregulated, and 35 mRNAs were downregulated. A total of six differentially expressed IncRNAs (ENST00000608897.1, ENST00000444196.1, ENST00000608741.1, XR_242163.1, ENST00000505196.1 and ENST00000498032.1) were randomly selected to validate the microarray data, which were consistent with the RT-qPCR analysis results. Differentially expressed mRNAs were enriched in important Gene Ontology terms and Kyoto Encyclopedia
\end{abstract}

Correspondence to: Professor Xin Wang, Department of Social Medicine and Public Health, School of Basic Medicine, Jiujiang University, 57 Xunyang East Road, Jiujiang, Jiangxi 332005, P.R. China

E-mail: wangxin2813@163.com

Abbreviations: lncRNA, long non-coding RNA; RT-qPCR, reverse transcription-quantitative PCR; NSCLC, non-small cell lung cancer; SCLC, small cell lung cancer; GO, Gene Ontology; KEGG, Kyoto Encyclopedia of Genes and Genomes; IGF1, insulin-like growth factor 1

Key words: daidzein, long non-coding RNA, microarray analysis, NSCLC, differential expression of Genes and Genomes pathways. Taken together, the results of the present study demonstrated that daidzein affected the expression level of lncRNAs in lung cancer cells, suggesting that daidzein may have potential effects on lung cancer cells.

\section{Introduction}

Lung cancer is one of the most common malignancies, that threatens the health and life of those affected. Lung cancer is the leading cause of cancer incidence and mortality in both men and women; it is estimated that there were 2.1 million new diagnosed cases and 1.8 million mortalities in 2018 worldwide (1,2). Lung cancer is classified into two major pathohistological subtypes, small cell lung cancer (SCLC) and non-small cell lung cancer (NSCLC) (3). NSCLC accounts $>85 \%$ of all cases of lung cancer (4). Despite major advancements in diagnosis and treatment, the incidence and mortality rates of lung cancer has remained high in recent years (5). Thus, it remains critical to identify and develop potential therapeutic targets in the hope of decreasing the risk of lung cancer.

A previous study demonstrated that consumption of legumes decreased the risk of lung cancer by $23 \%$ (6). Isoflavones, coumarins and lignin were reported to be the three main phytochemicals in soybeans (7). Currently, there is a focus on the potential health benefits of isoflavones, including genistein and daidzein. The effect of soybeans and their ingredients on tumors has become a hot topic (8), which could provide evidence on the preventive and protective effects of soybeans and their products for lung cancer.

Several long non-coding (lnc) RNAs and their biological functions have been identified with the use of high throughput technology (9). For example, BCYRN1 was found to function as a competing endogenous RNA to inhibit glioma progression by sponging microRNA-619-5p to regulate CUEDC2 expression and the PTEN/AKT/p21 pathway (10). Zhu et al (11) identified key lncRNAs in rectal adenocarcinoma using RNA sequencing and dysregulation of lncRNAs have been associated with lung cancer initiation and progression. IncRNAs play a vital role in regulating biological processes through epigenetic, transcriptional and post-transcriptional levels (12-15). Abnormal expression of lncRNAs have been associated with apoptosis, invasion and metastasis of lung cancer, which is conducive to the progression of lung cancer (16-18), and it has 
been demonstrated that lncRNAs act as effective markers for the diagnosis and prognosis of patients with lung cancer (19). Thus, the present study aimed to investigate the potential functions of daidzein on H1299 lung cancer cells by analyzing lncRNA and mRNA expression profiles, using microarray analysis. The results provide novel insight into the molecular mechanism of daidzein in lung cancer cell lines.

\section{Materials and methods}

Cell lines and cell culture. The human H1299 lung cancer cells were purchased from Wuhan University (Hubei, China). The cells were maintained in high-glucose medium supplemented with $10 \%$ fetal bovine serum (Haoyang Biological Products Technology Co., Ltd.) and $1 \%$ penicillin/streptomycin (Beijing Solarbio Science \& Technology Co., Ltd.), at $37^{\circ} \mathrm{C}$ in a humidified incubator with $5 \% \mathrm{CO}_{2}$.

Extraction of RNA from H1299 cells and RNA quality control. Total RNA was extracted from the H1299 cells using TRIzol ${ }^{\circledR}$ (Gibco; Thermo Fisher Scientific, Inc.), according to the manufacturer's protocol. A total of $4 \mathrm{ml}$ medium, supplemented with dimethyl sulfoxide (Beijing Solarbio Science \& Technology Co., Ltd.) was added to the cells in the control group for $24 \mathrm{~h}$ at $37^{\circ} \mathrm{C}$, while $4 \mathrm{ml} 10 \mu \mathrm{M}$ daidzein (Shanxi Huike Plant Development Co., Ltd.) was added to the cells in the treatment group for $24 \mathrm{~h}$ at $37^{\circ} \mathrm{C}$. The RNA was extracted from the cells in both groups after $24 \mathrm{~h}$. The purity and concentration of the RNA was determined from optical density 260/280 ratio using a spectrophotometer (NanoDrop ND-1000; Thermo Fisher Scientific, Inc.). RNA integrity was determined by $1 \%$ formaldehyde denaturing gel electrophoresis.

RNA labeling and microarray hybridization. cDNA labeled with fluorescent dyes (Cy5 and Cy3-dCTP) was produced using they Eberwine's linear RNA amplification method and subsequent enzymatic reaction, as previously described (20), which has also been improved using CapitalBio cRNA Amplification and Labeling kit (CapitalBio Technology, Inc.) to produce higher yields of labeled cDNA.

In detail, double-stranded cDNA (containing the T7 RNA polymerase promoter sequence) was synthesized from $1 \mu \mathrm{g}$ total RNA using the CbcScript reverse transcriptase according to the manufacturer's instructions (CapitalBio Technology, Inc.), with T7 Oligo (dT) and T7 Oligo (dN). Following double-stranded cDNA synthesis using DNA polymerase and RNase $\mathrm{H}$, the products were purified using a PCR NucleoSpin Extract II kit (Macherey-Nagel, GmbH and Co., KG) and eluted with $30 \mu 1$ elution buffer. The eluted double-stranded cDNA products were then vacuum evaporated to $16 \mu \mathrm{l}$ and reverse transcribed at $37^{\circ} \mathrm{C}$ for $14 \mathrm{~h}$ using a T7 Enzyme Mix. The amplified cRNA was purified using the RNA Clean-up kit (MN). The Klenow enzyme labeling method was used following RT using CbcScript II reverse transcriptase. Briefly, $2 \mu \mathrm{g}$ amplified RNA was mixed with $4 \mu \mathrm{g}$ random nanomer, denatured at $65^{\circ} \mathrm{C}$ for $5 \mathrm{~min}$, then cooled on ice. Subsequently, $5 \mu \mathrm{l}$ X first-strand buffer, $2 \mu 1$ $0.1 \mathrm{M}$ DTT and $1.5 \mu \mathrm{l} \mathrm{CbcScript}$ II reverse transcriptase was added, then the samples were incubated at $25^{\circ} \mathrm{C}$ for $10 \mathrm{~min}$, and $37^{\circ} \mathrm{C}$ for $90 \mathrm{~min}$. The cDNA products were purified using a PCR NucleoSpin Extract II kit (Macherey-Nagel, GmbH and
Co., KG), then vacuum evaporated to $14 \mu \mathrm{l}$. The cDNA was mixed with $4 \mu \mathrm{g}$ random nanomer, heated to $95^{\circ} \mathrm{C}$ for $3 \mathrm{~min}$, then snap cooled on ice for $5 \mathrm{~min}$. Next, $5 \mu \mathrm{l}$ Klenow buffer, dNTP and Cy5-dCTP or Cy3-dCTP (GE Healthcare) was added to a final concentration of $240 \mu \mathrm{M}$ each for the dNTPs and $40 \mu \mathrm{M}$ Cy-dCTP. A total of $1.2 \mu 1$ Klenow enzyme was then added and the samples were incubated at $37^{\circ} \mathrm{C}$ for $90 \mathrm{~min}$. The labeled cDNA was purified with a PCR NucleoSpin Extract II kit (Macherey-Nagel, GmbH and Co., KG) and resuspended in elution buffer. The labeled controls and test samples labeled with Cy5-dCTP and Cy3-dCTP were dissolved in $80 \mu 1$ hybridization solution containing 3 XSSC, $0.2 \%$ SDS, $5 X$ Denhardt's solution and $25 \%$ formamide. The DNA in the hybridization solution was denatured at $95^{\circ} \mathrm{C}$ for 3 min prior to loading onto a microarray. The arrays were hybridized in an Agilent Hybridization Oven (Agilent Technologies, Inc.) overnight at a rotation speed of $20 \mathrm{rpm}$ at $42^{\circ} \mathrm{C}$ then washed with two consecutive solutions (0.2\% SDS and $2 \mathrm{X} \mathrm{SSC}$ at $42^{\circ} \mathrm{C}$ for $5 \mathrm{~min}$, then $0.2 \mathrm{X} \mathrm{SSC}$ for $5 \mathrm{~min}$ at room temperature).

Microarray imaging and data analysis. The lncRNA + mRNA array data was analyzed for data summarization, normalization and quality control using the GeneSpring software v13.0 (Agilent Technologies, Inc.). To select the differentially expressed lncRNAs and mRNAs fold-change (FC) $\geq 2$ and $\leq-2$ and $\mathrm{P}<0.05$ (unpaired t-test). The data was $\log _{2}$ transformed and the median value was determined using the Adjust Data function in the CLUSTER v3.0 software (http://bonsai.hgc. $\mathrm{jp} / \sim$ mdehoon/software/cluster/software.htm), then further analyzed using hierarchical clustering with average linkage (21). Finally, tree visualization was performed using Java Treeview (Stanford University School of Medicine). Kyoto Encyclopedia of Genes and Genomes (KEGG) (https://www. genome.jp/kegg/) and Gene Ontology (GO) (http://www. geneongoloty.org/) analyses were performed to determine the function of differentially expressed mRNAs in biological pathways and GO terms (with a cut-off of $\mathrm{P}<0.05$ ). After gene annotation function, STRING (Search Tool for the Retrieval of Interacting Genes/Proteins; https://string-db.org/) was used to identify the relationship between protein expression levels, in which a protein-protein interaction network was created.

Co-expression analysis and transcription factor prediction. Co-expression analysis is used to perform correlation analysis on the signal value trend of differential expressed lncRNA and mRNA in all samples (experimental group and control group) after comparison. Correlation, $>0.99$ or $<-0.99$ was used as the screening criteria, with $\mathrm{P}<0.05$. The lncRNA/mRNA relationship pair, that met the aforementioned conditions was considered to have a co expression relationship. Transcription factor prediction (TFs_predict), which uses the Match-1.0 Public (http://gene-regulation.com/pub/programs.htm1\%23match) transcription factor prediction tool, was used to predict the binding sites of TFs, 2,000 bp upstream and 500 bp downstream of the start site of each lncRNA based on the co-expression results, and network diagrams are created using Cytoscape (http://www. cytoscape.org/download.php) software.

RT-quantitative PCR (RT-qPCR). Total RNA from the cell cultures was extracted using TRIzol ${ }^{\circledR}$ (Invitrogen; Thermo 
Table I. Primer sequences used for lncRNAs and mRNAs in reverse transcription-quantitative PCR.

\begin{tabular}{lll}
\hline Name & \multicolumn{1}{c}{ Forward primer sequence (5'-3') } & Reverse primer sequence (5'-3') \\
\hline ENST00000608897.1 & GTGCAAATACAGGCCAAGTCAG & TCCCCAAAAAGATGCCAAGG \\
ENST00000444196.1 & TCGTGTGATCTGCCAGTTTC & TGGAAGGCAGGATTTTGACC \\
ENST00000608741.1 & TCTTCCTGGTGCACTCAGATG & TTGCAGTCCTAACGCGACTC \\
XR_242163.1 & CATACGAGATGGAGATATCATCC & CAAATTCTTCTTCTCTAAGATG \\
ENST00000505196.1 & AGCCCGGAAATAAGAATGGC & TTCTGGCCTGTGATGAACTCC \\
ENST00000498032.1 & TCAAGAGACCGAGACCATCC & CTCACTACAAGCTCCGCCT \\
ROPN1L & TGTGCCTGCCGAAGGAAAAAT & GTTCAAGGACCCACCAAGCAT \\
FANCC & CTGCCATATTCCGGGTTGTTG & AGCACTGCGTAAACACCTGAA \\
FAM149B1 & ATCTACTGAAGGAAGCTCGGAC & CACACTCAACTTCTGCTCATACA \\
TRHR & CCAAACACAGCTTCAGCCAC & GGCTCACCAGGTAGCAGTTT \\
IGF1 & GCTCTTCAGTTCGTGTGTGGA & GCCTCCTTAGATCACAGCTCC \\
TTN & CCCCATCGCCCATAAGACAC & CCACGTAGCCCTCTTGCTTC \\
GAPDH & GGAGTCCACTGGCGTCTTCA & GTCATGAGTCCTTCCACGATACC
\end{tabular}

lnc, long non-coding.

Fisher Scientific, Inc.), reverse transcribed into cDNA using the EasyScript $^{\circledR}$ One-Step gDNA Removal and cDNA Synthesis SuperMix kit (TransGen Biotech Co., Ltd.) for $15 \mathrm{~min}$ at $42^{\circ} \mathrm{C}$, $5 \mathrm{sec}$ at $85^{\circ} \mathrm{C}$, then stored at $4^{\circ} \mathrm{C}$ until further use. qPCR was performed on a CFX Connect Real-Time system (Bio-Rad Laboratories, Inc.) with TransStart ${ }^{\circledR}$ Top Green qPCR SuperMix (TransGen Biotech Co., Ltd.), according to the manufacturer's protocol. GAPDH served as an internal control and was included in the same PCR reaction with differentially expressed lncRNAs and mRNAs for RT-qPCR. The primer sequences used for the qPCR of the lncRNAs and mRNAs are listed in Table I. Relative expression levels were quantified using the $2^{-\Delta \Delta \mathrm{Cq}}$ method (22).

Statistical analysis. Statistical analysis was performed using SPSS 19.0 software (IBM Corp.). The data are presented as the mean \pm SD. Differences between groups were assessed using a two tailed unpaired t-test. $\mathrm{P}<0.05$ was considered to indicate a statistically significant difference.

\section{Results}

In vitro experiments. The preliminary in vitro experiments showed that daidzein had the strongest inhibitory effect on the proliferation of H1299 cells (data not shown); therefore, these cells were used for further experiments. The soybean isoflavones were extracted, which are the active ingredients in legumes, and daidzein and its derivatives were synthesized and purified. The experimental flow chart of the present study is presented in Fig. 1.

Overview of lncRNAs and mRNAs profiles. The present study aimed to investigate the effect of daidzein on H1299 cells. Gene cluster analysis of the mRNAs and lncRNAs was performed following treatment with daidzein. The clustering map demonstrated similarities between the samples.

As presented in Fig. 2, a significant difference in both mRNAs and lncRNAs was observed between the experimental group of cells treated with daidzein and the control group of untreated with daidzein. Following the addition of daidzein, the expression level of eight lncRNAs was upregulated in the H1299 cells, while 111 lncRNAs were downregulated. In addition, five mRNAs were upregulated and 35 mRNAs were downregulated. In Fig. 2A and D, the top sample tree represents the similarity clustering relationship between the different samples. The top color block represents the expected grouping of the samples manually set prior to the cluster analysis, and the samples of the same color indicate that the experiment is expected to be a group. The red line in Fig. 2B and E, X2, is the threshold boundary line of the upregulated lncRNA/mRNAs, while the green line $\mathrm{X}(-2)$ is the threshold boundary line of the downregulated lncRNA/mRNAs, and the middle gray line is the fitted line of the overall expression amount. The equation in is the fitted line equation, and $\mathrm{R}$ represents the correlation coefficient between the two sets of samples.

KEGG pathway enrichment and $G O$ analysis. Microarray analysis revealed that 40 mRNAs (5 upregulated and 35 downregulated) were significantly differentially expressed in the H1299 cell line treated with daidzein compared with that in the cells treated without daidzein $(\mathrm{FC} \geq 2.0 ; \mathrm{P}<0.05)$. The top 20 significantly enriched KEGG pathway and disease terms were selected. The top three terms that were enriched for gene-affected diseases following daidzein treatment were: 'Erythropoietic protoporphyrin', 'malignant pleural mesothelioma' and 'distal myopathy'. The addition of daidzein also affected the genes involved in diseases, including cancer of the lung and pleura, the results of which were consistent with the research model (Fig. 3A). KEGG pathway analysis revealed that 'dilated cardiomyopathy' (hsa05414), 'hypertrophic cardiomyopathy' (hsa05410), 'long-term depression' (hsa04730), 'p53 signaling pathway' (hsa04115) were included in the top 20 pathways (Fig. 3B).

As shown in Fig. 4, numerous differentially expressed mRNAs, compared with that to the background mRNAs, 


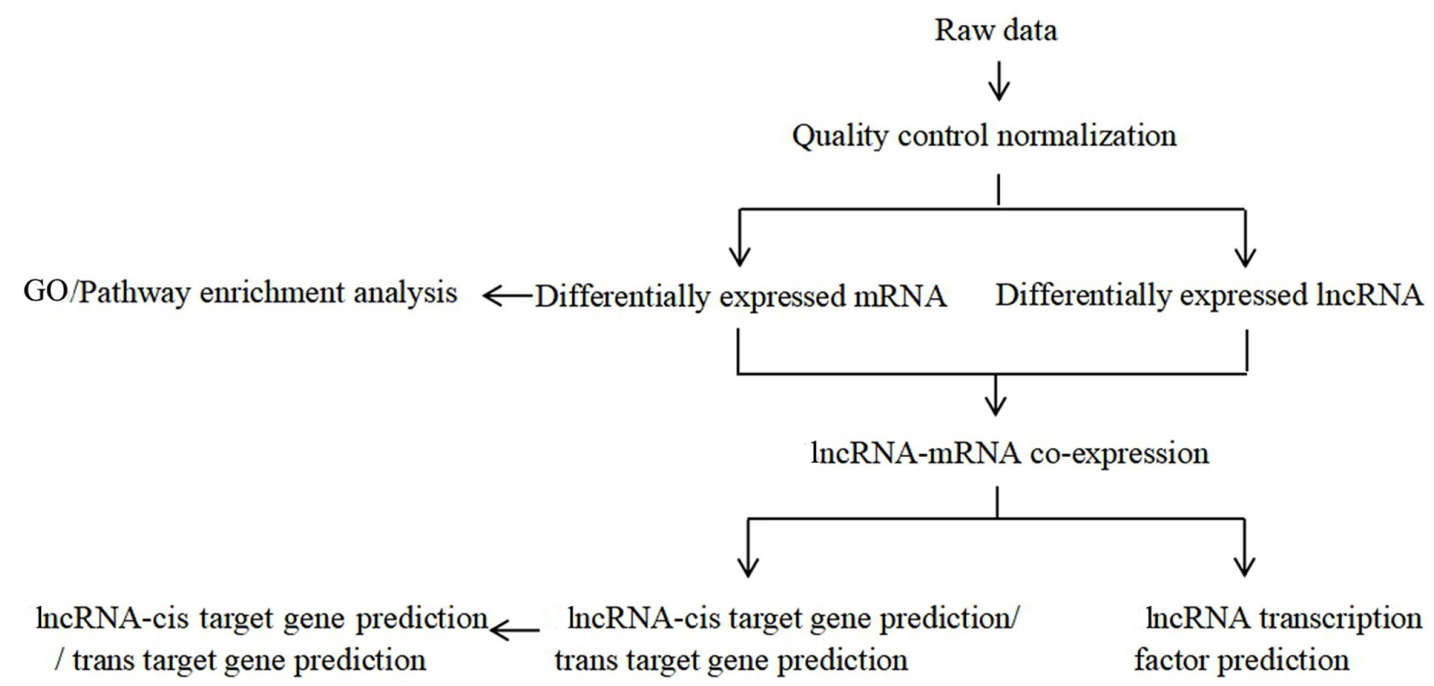

Figure 1. Flow chart of the analysis performed in the present study. lnc, long non-coding; GO, Gene Ontology; KEGG, Kyoto Encyclopedia of Genes and Genomes.

were enriched in biological processes, molecular function and cellular component categories, and the top 20 significantly enriched terms were selected from GO analysis. The results (Fig. 5) indicated that the most significantly enriched GO terms associated with the differentially expressed mRNAs were 'detection of mechanical stimulus' (biological processes; GO:0050982; P=0.0010488989), 'condensed chromosome' (cellular component; GO:0000793; $\mathrm{P}=0.0012408009$ ), ' $\alpha$-actinin binding' (molecular function; GO:0051393; $\mathrm{P}=0.0002475636)$. Several of the differentially expressed genes were localized in the cytoplasm and altered the expression of molecular functional genes associated with 'binding'.

Co-expression analysis. Co-expression analysis was performed to determine the association between IncRNA and mRNA pairs, with similar expression profiles, at the genomic level. The association between differentially expressed mRNAs and lncRNAs following the addition of daidzein is presented in Fig. S1A. Following the addition of daidzein, the co-expressed mRNAs with differentially expressed lncRNAs included: XLOC_I2_013457, LOC284825, CIQTNF3, FILP1, FANCC, SPATA4, FLJ41455, ANKRD12, SYCP2, RTKN2 and MTHFD2L.

Transcription factor prediction. The transcription factor was predicted (TFs_predict) using the Match-1.0 Public transcription factor prediction tool (Fig. S1B). Based on the co-expression results, the binding of transcription factors, 2,000 bp upstream and 500 bp downstream of each lncRNA initiation sites was predicted. The relevant transcription factors of differentially expressed lncRNAs, following the addition of daidzein to the H1299 cells, included Oct-1, HNF-1, HNF-4, Pax-4, COMP1, Pax-6, FOXD3 and FOXJ2.

RT-qPCR validation of microarray data. A total of six differentially expressed lncRNAs and six mRNAs were randomly selected to validate the microarray data. RT-qPCR analysis was performed to determine the fold changes of selected IncRNAs and mRNAs, respectively (Fig. 6). The fold-change was positive when the expression was upregulated and negative when the expression was downregulated. Thus, the RT-qPCR results were consistent with the microarray data.

Construction of core gene interaction protein association. As presented in Fig. 7, the somatostatin C protein encoded by the insulin-like growth factor-1 (IGF1) gene interacted directly with the IGF1 receptor, IRS, AKT and caspase-9 proteins. Collectively, these results suggested that the IGF1 gene plays an important role in the development of tumors.

\section{Discussion}

Lung cancer is one of the most common malignant tumors, that threatens the health and life of those affected (23). Due to the complexity of its molecular mechanisms, there has been an increased effort to identify early and accurate prevention, diagnosis and treatment to decrease the mortality rate (24). Previous studies have demonstrated that soy products inhibit tumor development (25-30). An epidemiological study reported that soy-related foods can decrease the risk of lung cancer mortality (31). A previous study demonstrated that isoflavones were also associated with a decreased risk of lung cancer, both in vivo and in vitro (32); however, the specific molecular mechanism remains unclear. In addition, gene chip technology has enabled the investigation of differential gene expression, particularly in the identification of tumor differential genes $(33,34)$.

A previous study reported that lncRNAs were differentially expressed in normal and cancer cells (35). IncRNAs are non-coding RNA molecules, 200 nucleotides in length (36). Aberrant lncRNA expression is a major characteristic of several types of cancer, which has been demonstrated to play an important role in promoting the development and progression of human cancer (37). For example, upregulated expression of the carcinogenic IncRNA, HOTAIR has been associated with breast, colorectal and liver cancers $(38,39)$. Zhang et al (40) demonstrated that overexpression of IncRNA, UFC1 promoted the proliferation and migration of gastric cancer cells. The association between lncRNA and lung cancer has also been 


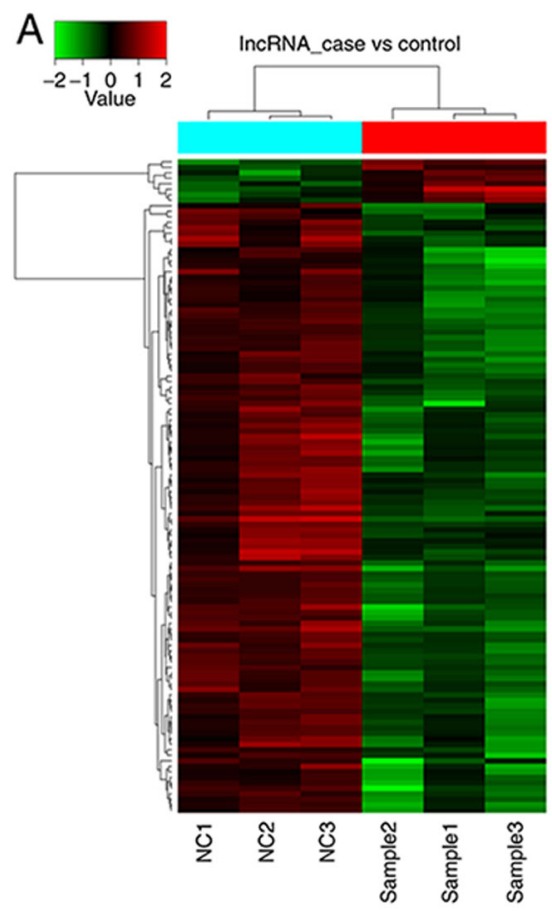

B

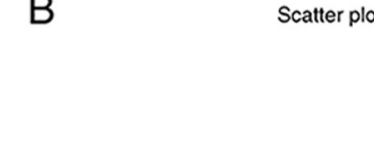

C

Volcano plot
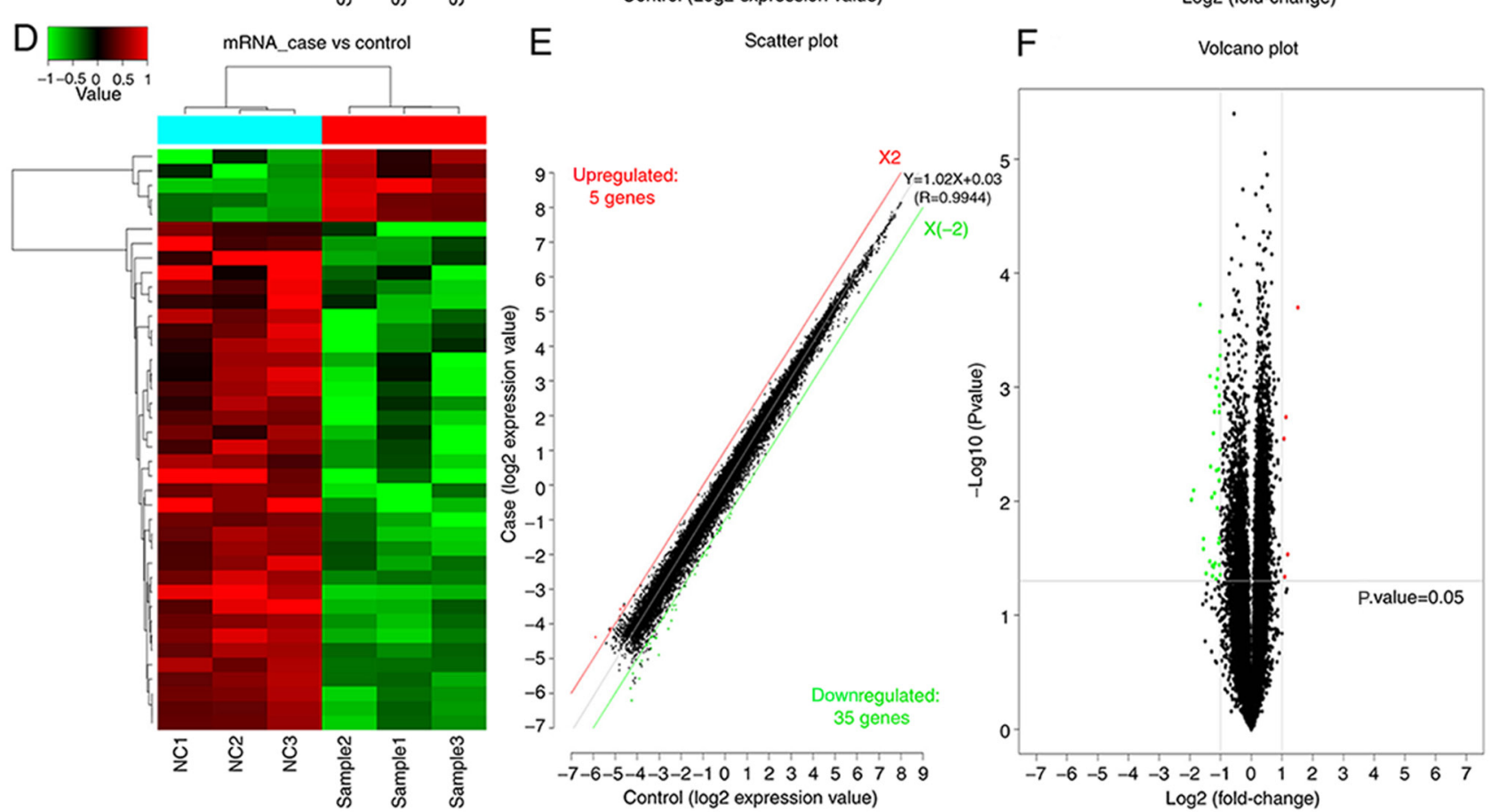

$\mathrm{F}$

Volcano plot

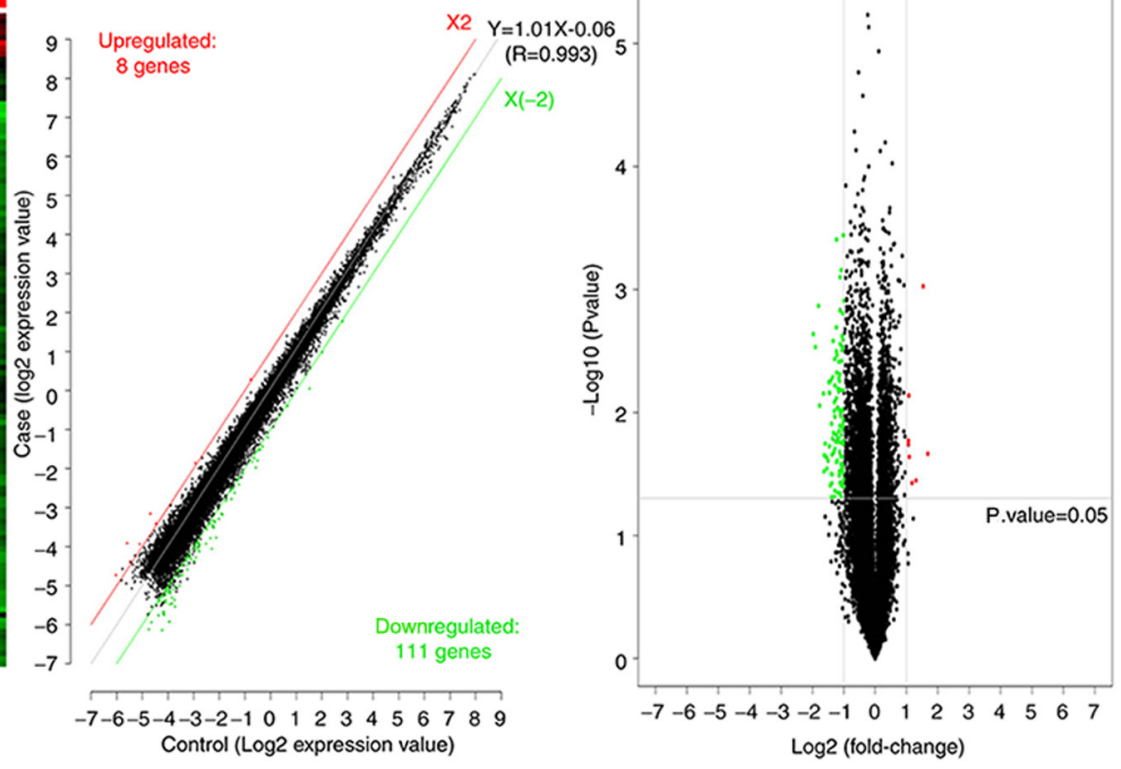

Figure 2. Sample analysis of differentially expressed lncRNAs and mRNAs from the H1299 cell line treated with and without daidzein. (A and D) lncRNA and mRNA expression profiles. Each column represents a sample, while each row represents the degree of expression of a lncRNA or mRNA in a different sample. Red denotes high expression level, while green denotes low expression. (B and E) Scatter plots of the up- and downregulated lncRNA and mRNAs with equations and log-converted values. The number of up- and downregulated lncRNA and mRNAs are presented in the upper left and lower right corners, respectively. (C and F) Volcano plots showing the up- and downregulated lncRNA/mRNAs. The abscissa is - $\log _{10}\left(\right.$ P-values) and the ordinate is $\log _{2}$ (fold-change). Red denotes the upregulated lncRNA/mRNAs, while green denotes the downregulated lncRNA/mRNAs, and black denotes no significant difference in gene expression. NC, non-treated control; lnc, long non-coding.

extensively investigated (41-43). However, there is lack of research into the molecular mechanism of action of soybean and its products on lung cancer cells, using the expression profile data of microarray.

The present study analyzed the difference in mRNA and lncRNA expression levels between daidzein-treated and -untreated H1299 lung cancer cells, based on the original results of the gene chip. Bioinformatics (KEGG enrichment and GO analyses) and RT-qPCR were performed to observe the expression of differential genes to further investigate the molecular mechanism of soy isoflavones and their derivatives in NSCLC. Sample clustering demonstrated that there was a significant difference between the experimental and the control groups, suggesting that daidzein could significantly affect the IncRNA and mRNA expression levels in lung cancer cells. The results of this experiment demonstrated that following 
A

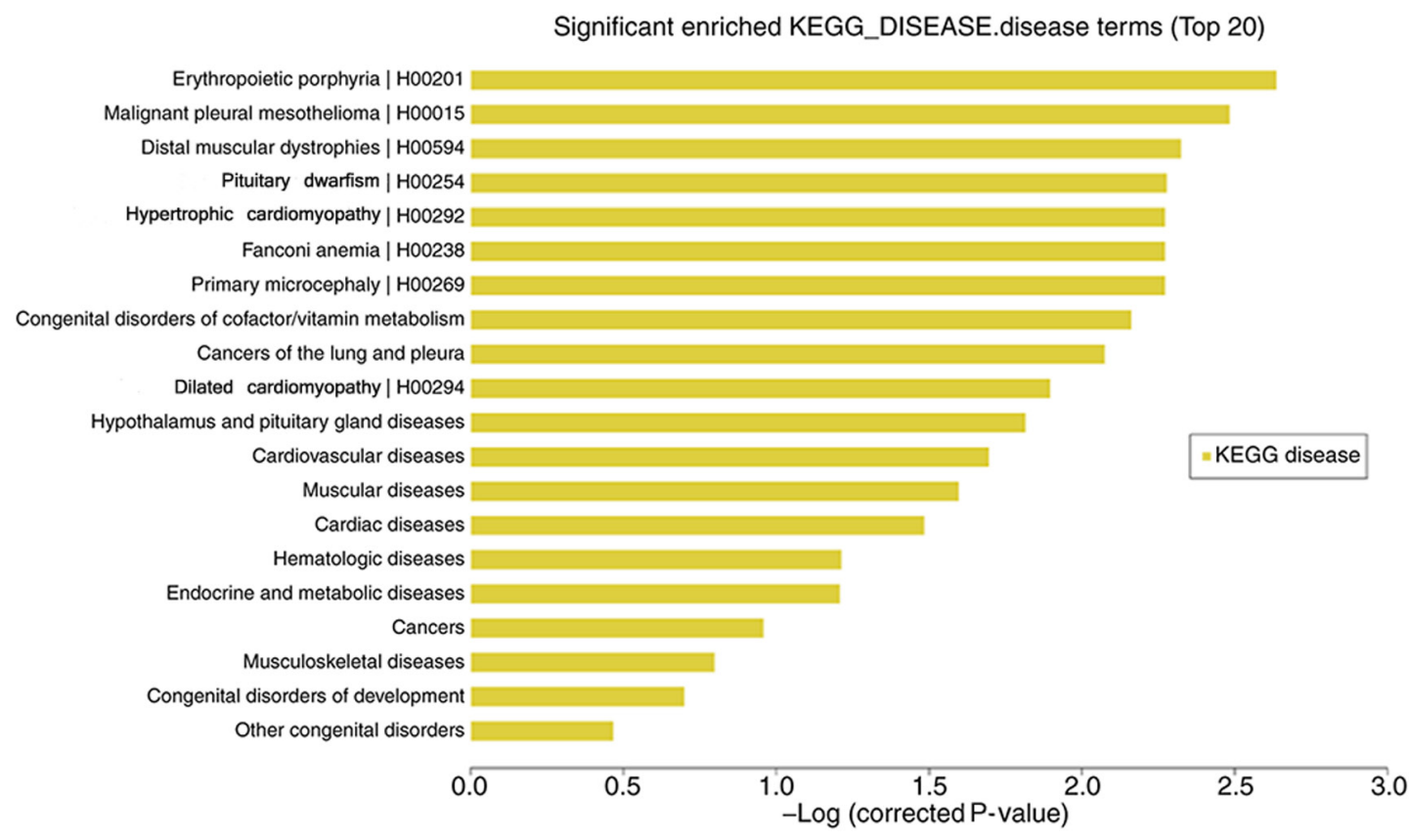

B

Significant enriched KEGG_PATHWAY.pathway terms (Top 20)

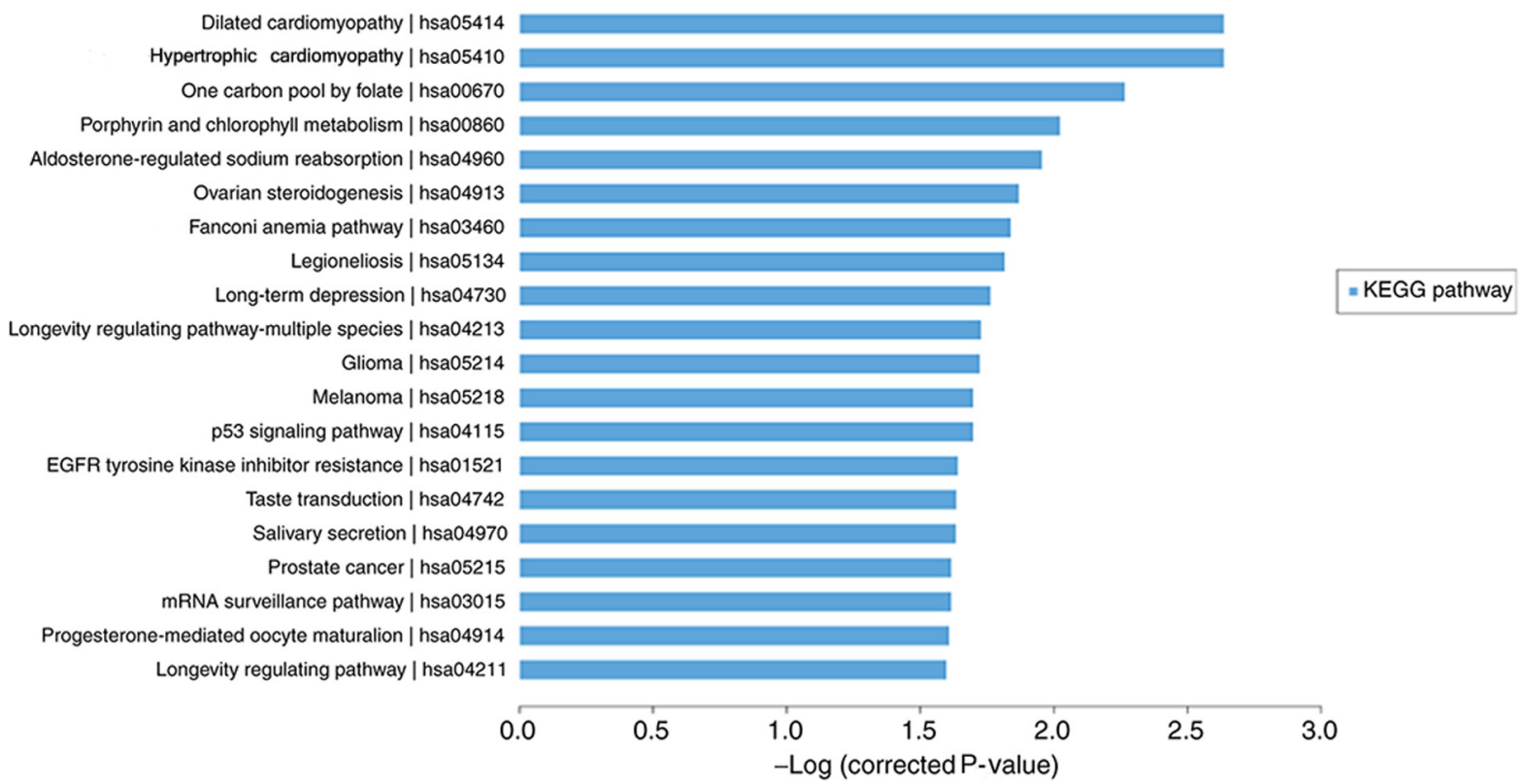

Figure 3. Enrichment analysis of differentially expressed mRNAs. The top 20 significantly enriched (A) disease terms and (B) pathway terms were selected. The-log (corrected P-value) indicates the significance of the KEGG disease terms and pathways. KEGG, Kyoto Encyclopedia of Genes and Genomes.

treatment with daidzein, eight and 11 lncRNAs were up- and downregulated in H1299 lung cancer cells, respectively. In addition, five and 35 mRNAs were up- and downregulated, respectively. To obtain preliminary insights into lncRNA target gene function, GO and KEGG enrichment analyses were performed using the lncRNA target gene pool. KEGG analysis of the differentially expressed lncRNAs identified the top 20 diseases associated, which included cancers of the lung and pleura and malignant pleural mesothelioma diseases. KEGG analysis also demonstrated that the addition of daidzein affected the pathways involved in cancer-associated genes, namely the P53 signaling pathway, suggesting that the addition of daidzein could affect tumor proliferation. GO analysis revealed that the genes involved in stress-related biological processes changed following addition of daidzein to lung cancer cells. Several of the differentially expressed genes were localized in the cytoplasm and altered the expression of molecular functional genes associated with 'binding'. Collectively, these results suggested that the molecular mechanism of action of daidzein in the lung cancer cells may be associated with the alteration of molecular functions associated with 'binding' in the cytoplasm. RT-q PCR was performed using six randomly selected lncRNAs and mRNAs in samples from a lung cancer cell line to validate the microarray results. A total of six lncRNAs and mRNAs 


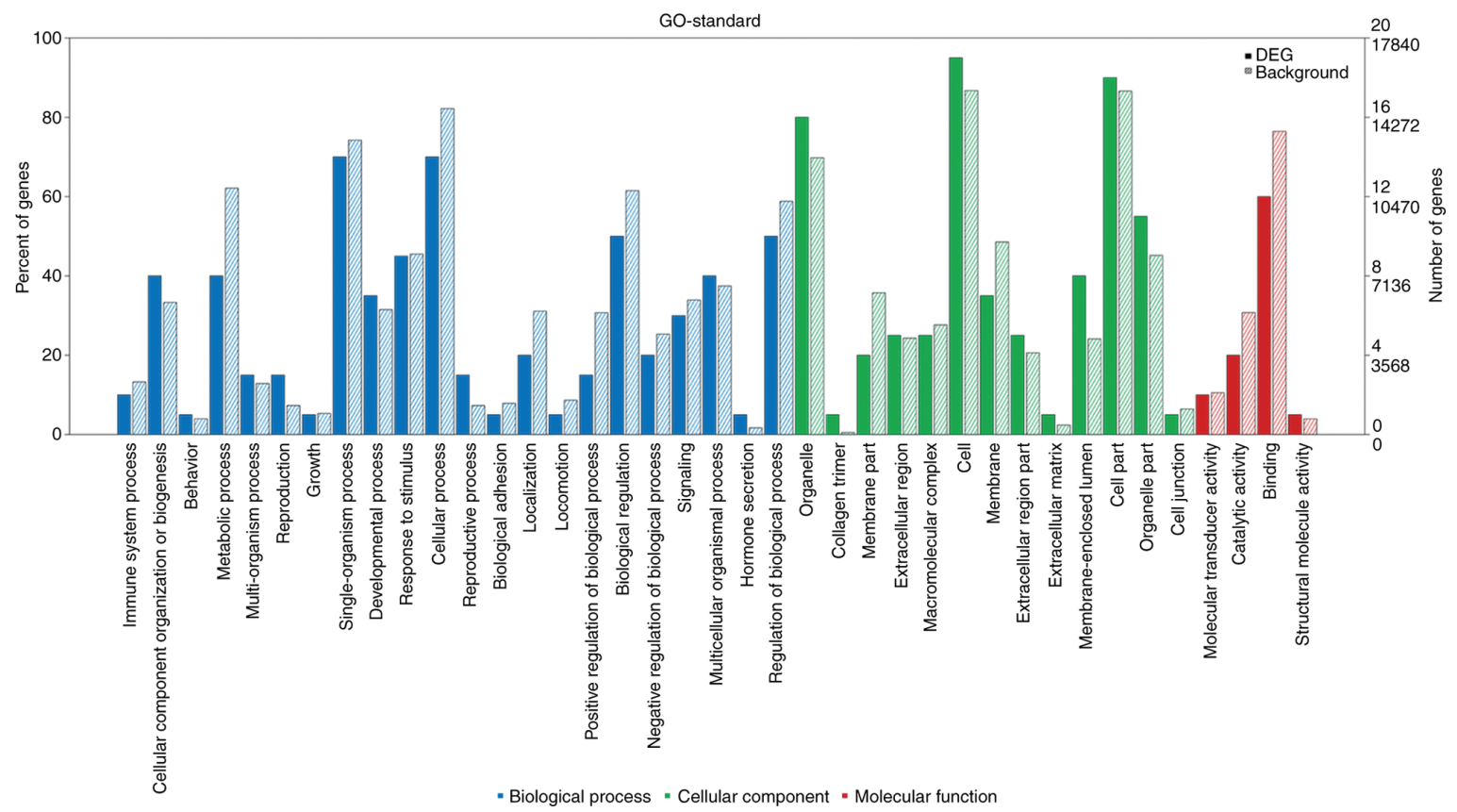

Figure 4. GO analysis of the differentially expressed mRNAs. Frequency analysis graph of secondary items of GO analysis includes biological processes, cellular component and molecular function. The percentage and number of the genes is shown on the left and right vertical axis respectively. GO, Gene Ontology.

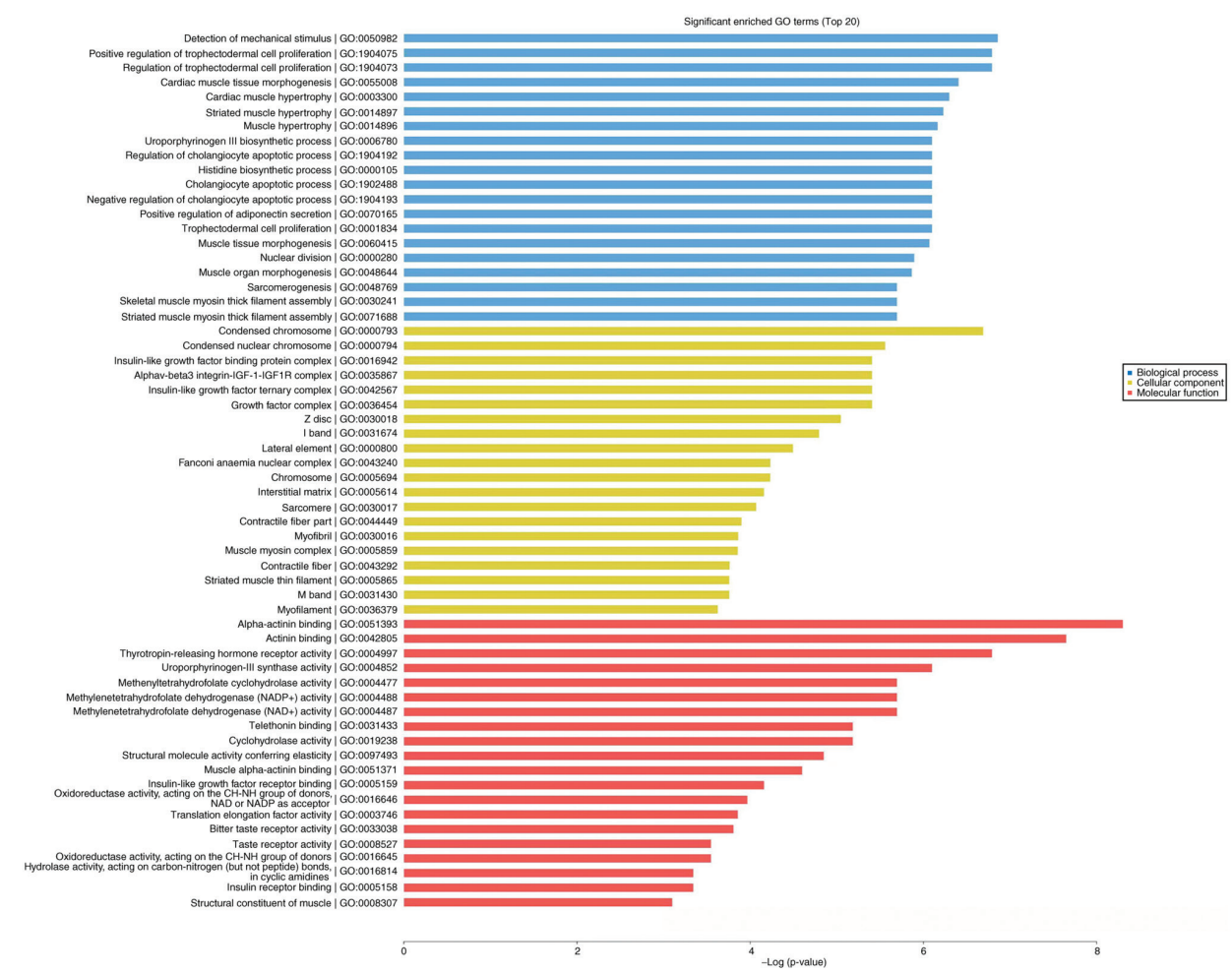

Figure 5. GO enrichment analysis results (top 20) for BP, MF and CC of differentially expressed mRNAs in H1299 lung cancer cells treated with daidzein. P-values are shown.

identified in the microarray analysis were confirmed to be aberrantly expressed in lung cancer cells via RT-qPCR analysis.

As lung cancer is a serious threat to human health, researchers have been investigating the molecular mechanisms that inhibit lung cancer from all aspects, including the proliferation, invasion, metastasis, autophagy and apoptosis of lung cancer cells (44-47). There are several studies investigating the apoptotic mechanism associated with the p53 gene (48-50). It is well-known that p53 plays a key role in inducing apoptosis in numerous types of cancer, such as lung, gastric and prostate cancers (51-53). In a previous study, daidzein inhibited the proliferation and NF- $\mathrm{KB}$ signaling pathway in lung cancer cells (54). 

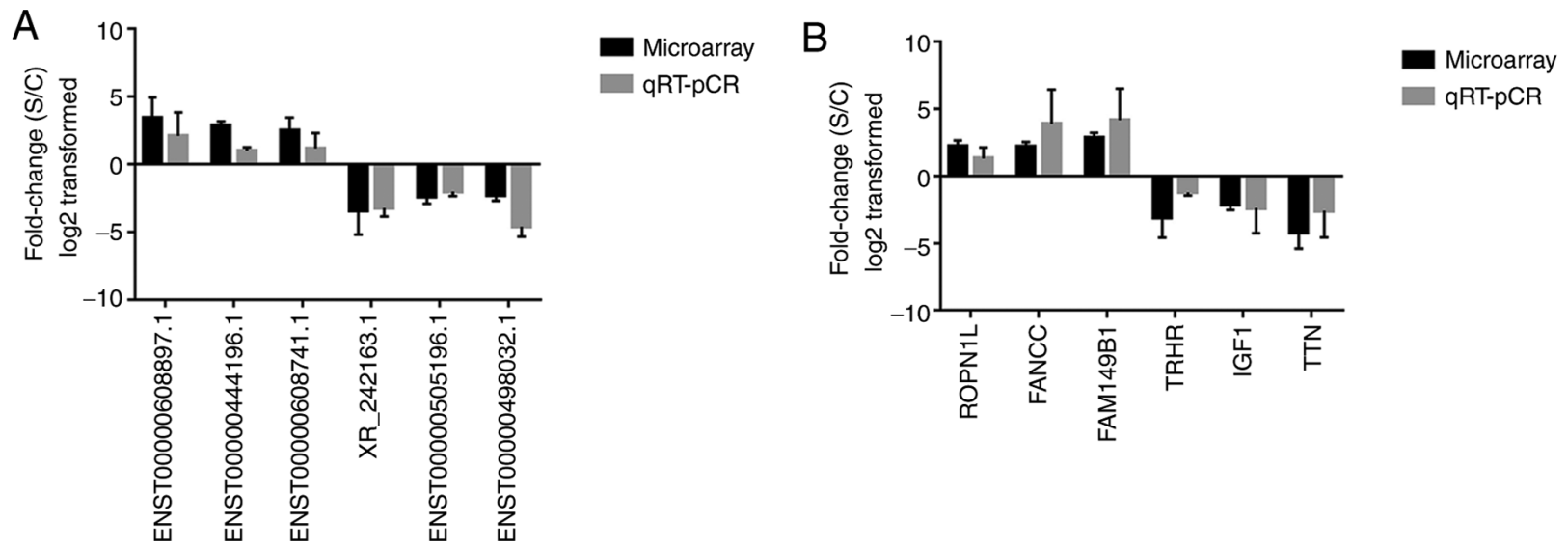

Figure 6. Expression level of lncRNAs and mRNAs from the H1299 cell line treated with and without daidzein. The validation of six (A) lncRNAs and (B) mRNAs using RT-qPCR. Data are presented as the mean \pm SD. lnc, long non-coding; S, sample (H1299 cells treated with daidzein); C, control (H1299 cells without treatment); RT-qPCR; reverse transcription-quantitative PCR.

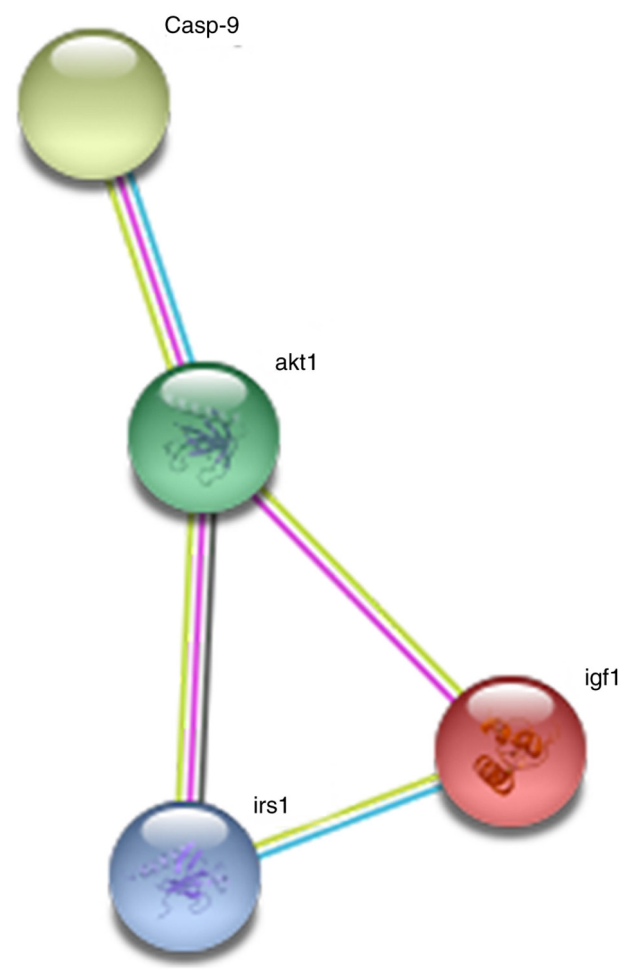

Figure 7. Protein-protein interaction network of the pathways from the differentially expressed mRNAs.

Therefore, it was hypothesized that daidzein could promote the apoptosis of cancer cells via the P53 apoptosis pathway, which could inhibit the proliferation of lung cancer cells. From the microarray analysis, in the present study, the P53 pathway was included in the top 20 pathways with differential gene enrichment, which provides a potential mechanism for future research, to further identify the specific mechanism involved.

Previous studies have demonstrated that high IGF1 expression level was associated with an increased risk of breast, prostate, colorectal and lung cancers (55-58). In addition, the IGF-binding protein, that regulates the IGF1 gene, has been found to have proapoptotic activities, both dependent and independent of p53 (59). Zhang et al (60) reported that the IGF1 receptor plays a key role in radiation-induced apoptosis of lung cancer cells. Furthermore, a previous study demonstrated that the occurrence of lung cancer is associated with the dysregulation of IGF1, which affects the tumor suppressor gene, p53 (61). Consistent with these previous findings, the results of the present study demonstrated that IGF1 was differentially expressed and the addition of daidzein to the lung cancer cell line affected the p53 signaling pathway.

The present study has two major limitations. First, the study only focused on the H1299 cell line of NSCLC; therefore, other NSCLC cell lines and those from SCLC will also be investigated in future research. Second, the present study lacks clinical data, which will be also be included in future studies to validate the results in the present study.

It has been hypothesized that IGF1 also plays a key role in the effects of daidzein in lung cancer. The present study constructed a protein-protein interaction network of the IGF1 gene using the STRING online database. The results suggested that IGF1 could mediate apoptosis by interacting with other genes in cancer-related pathways, thereby inhibiting tumor cell proliferation. This IGF1 protein forms a signaling pathway with the IGF1 receptor, IRS, AKT and caspase- 9 proteins. Notably, IGF1 or a protein that interacted with IGF1 was involved in malignant tumors via the $\mathrm{PI} 3 \mathrm{~K} / \mathrm{pAKT}$ pathway $(62,63) \mathrm{AKT}$, also known as protein kinase $\mathrm{B}$ or Rac, is an oncogenic protein, that plays an important role in cell survival and apoptosis (64). Insulin growth factors and survival factors, including nerve growth factor and peptide trophic factors could activate the AKT signaling pathway (65). Abnormal expression of AKT and overactivation of AKT-associated pathways have been found to be involved in the development of different types of cancer, including lung, breast, ovarian and pancreatic cancers, and have been associated with the proliferation and survival of lung cancer cells and apoptosis (66-69). Taken together, these findings suggested that the AKT signaling pathway could be used as a therapeutic target for lung cancer.

In mammalian cells, one of the endogenous pathways of apoptosis is the activation of caspase-9 (70). Caspases are proteolytic enzymes, that are involved in cell apoptosis. Caspase-9 is one of the most critical components of apoptosis 
in the caspase family (54). Previous studies have provided valuable insight for the potential of daidzein to induce apoptosis via different pathways and delay the progression of lung cancer $(71,72)$. Thus, the IGF1 gene has been considered as a promising candidate gene, and the gene network should be the focus of follow-up research on the molecular mechanism of soybean action in lung cancer. Collectively, the results of the present study provide a novel biomarker for the treatment of lung cancer; however, further research is required to validate the results.

In conclusion, the results of the present study revealed a set of lncRNAs which were differentially expressed in lung cancer cells following treatment with daidzein. Taken together, these findings suggested that daidzein could significantly affect lncRNA expression in lung cancer cells. Furthermore, the results also demonstrated that the molecular mechanism of action of daidzein in lung cancer cells may be associated with the alteration of molecular functions associated with 'binding' in the cytoplasm. The results presented here provide novel insight into the molecular mechanism of daidzein in the H1299 lung cancer cell line. In addition, genes were also identified that were co-expressed with mRNAs, as well as transcription factors predicted by lncRNAs, and promising core genes and signaling pathways. Collectively, the present study provided novel insights into the molecular mechanism of lncRNAs associated with the effect of daidzein in lung cancer and suggested that daidzein may effectively delay the progression of lung cancer.

\section{Acknowledgements}

Not applicable.

\section{Funding}

The present study was supported by the Natural Science Foundation of Jiangxi Province (grant no. 2020BAB206067).

\section{Availability of data and materials}

The datasets generated and/or analyzed during the current study are available from the corresponding author on reasonable request. The high-throughput sequencing data is publicly available from the GEO database (accession no. GSE181093).

\section{Authors' contributions}

LFL, SXH, XW and JL conceived and designed the present study. LFL drafted the initial manuscript. LFL performed the experiments, data collection, and wrote the manuscript. XWX and SXH contributed to the methodology, performed the experiments and analyzed the data. XBW contributed to data collection and analyzed the data. All authors have read and approved the final manuscript. XWX and $\mathrm{SXH}$ obtained materials and confirm the authenticity of all the raw data.

\section{Ethics approval and consent to participate}

Not applicable.

\section{Patient consent for publication}

Not applicable.

\section{Competing interests}

The authors declare that they have no competing interests.

\section{References}

1. Mattiuzzi C and Lippi G: Current cancer epidemiology. J Epidemiol Glob Health 9: 217-222, 2019.

2. Chen W, Sun K, Zheng R, Zeng H, Zhang S, Xia C, Yang Z, Li H, Zou X and He J: Cancer incidence and mortality in China, 2014. Chin J Cancer Res 30: 1-12, 2018.

3. Davidson MR, Gazdar AF and Clarke BE: The pivotal role of pathology in the management of lung cancer. J Thorac Dis 5 (Suppl 5): S463-S478, 2013.

4. Chen Z, Fillmore CM, Hammerman PS, Kim CF and Wong KK: Non-small-cell lung cancers: A heterogeneous set of diseases. Nat Rev Cancer 14: 535-546, 2014.

5. Gridelli C, Rossi A and Maione P: Treatment of non-small-cell lung cancer: State of the art and development of new biologic agents. Oncogene 22: 6629-6638, 2003.

6. Yang G, Shu XO, Chow WH, Zhang X, Li HL, Ji BT, Cai H, Wu S, Gao YT and Zheng W: Soy food intake and risk of lung cancer: Evidence from the shanghai women's health study and a meta-analysis. Am J Epidemiol 176: 846-855, 2012.

7. Benassayag C, Perrot-Applanat M and Ferre F: Phytoestrogens as modulators of steroid action in target cells. J Chromatogr B Analyt Technol Biomed Life Sci 777: 233-248, 2002.

8. Andres S, Abraham K, Appel KE and Lampen A: Risks and benefits of dietary isoflavones for cancer. Crit Rev Toxicol 41: 463-506, 2011.

9. Peng F, Wang R, Zhang Y, Zhao Z, Zhou W, Chang Z, Liang H, Zhao W, Qi L, Guo Z and Gu Y: Differential expression analysis at the individual level reveals a lncRNA prognostic signature for lung adenocarcinoma. Mol Cancer 16: 98, 2017.

10. Mu M, Niu W, Zhang X, Hu S and Niu C: LncRNA BCYRN1 inhibits glioma tumorigenesis by competitively binding with miR-619-5p to regulate CUEDC2 expression and the PTEN/AKT/p21 pathway. Oncogene 39: 6879-6892, 2020.

11. Zhu X, Wang D, Lin Q, Wu G, Yuan S, Ye F and Fan Q: Screening key lncRNAs for human rectal adenocarcinoma based on lncRNA-mRNA functional synergistic network. Cancer Med 8: 3875-3891, 2019.

12. Wang Z, Yang B, Zhang M, Guo W, Wu Z, Wang Y, Jia L, Li S, Cancer Genome Atlas Research Network; Xie W and Yang D: lncRNA epigenetic landscape analysis identifies EPIC1 as an oncogenic lncRNA that interacts with MYC and promotes cell-cycle progression in cancer. Cancer Cell 33: 706-720, 2018.

13. Hauptman $\mathrm{N}$ and Glavač D: Long non-coding RNA in cancer. Int J Mol Sci 14: 4655-4669, 2013.

14. Bao Z, Yang Z, Huang Z, Zhou Y, Cui Q and Dong D: LncRNADisease 2.0: An updated database of long non-coding RNA-associated diseases. Nucleic Acids Res 47: D1034-D1037, 2019.

15. Chen G, Wang Z, Wang D, Qiu C, Liu M, Chen X, Zhang Q, Yan $G$ and Cui Q: LncRNADisease: A database for long-non-coding RNA-associated diseases. Nucleic Acids Res 41: D983-D986, 2013.

16. Tokgun $\mathrm{O}$, Tokgun PE, Inci $\mathrm{K}$ and Akca $\mathrm{H}$ : lncRNAs as potential targets in small cell lung cancer: MYC-dependent regulation. Anticancer Agents Med Chem 20: 2074-2081, 2020.

17. Lu T, Wang Y, Chen D, Liu J and Jiao W: Potential clinical application of lncRNAs in non-small cell lung cancer. Onco Targets Ther 11: 8045-8052, 2018.

18. Lai XN, Li J, Tang LB, Chen WT, Zhang L and Xiong LX: miRNAs and LncRNAs: Dual roles in TGF- $\beta$ signaling-regulated metastasis in lung cancer. Int J Mol Sci 21: 1193, 2020.

19. Wang M, Ma X, Zhu C, Guo L, Li Q, Liu M and Zhang J: The prognostic value of long non coding RNAs in non small cell lung cancer: A meta-analysis. Oncotarget 7: 81292-81304, 2016. 
20. Patterson TA, Lobenhofer EK, Fulmer-Smentek SB, Collins PJ, Chu TM, Bao W, Fang H, Kawasaki ES, Hager J, Tikhonova IR, et al: Performance comparison of one-color and two-color platforms within the microarray quality control (MAQC) project. Nat Biotechnol 24: 1140-1150, 2006.

21. Eisen MB, Spellman PT, Brown PO and Botstein D: Cluster analysis and display of genome-wide expression patterns. Proc Natl Acad Sci U S A 95: 14863-14868, 1998.

22. Li QW, Ma L, Qiu B, Yang H, Zhu YJ, Qiang MY, Liu SR, Chen NB, Guo JY, Cai LZ, et al: Differential expression profiles of long noncoding RNAs in synchronous multiple and solitary primary esophageal squamous cell carcinomas: A microarray analysis. J Cell Biochem: Oct 15, 2018 (Epub ahead of print).

23. Siegel RL, Miller KD and Jemal A: Cancer statistics, 2019. CA Cancer J Clin 69: 7-34, 2019.

24. Gong WJ, Peng JB, Yin JY, Li XP, Zheng W, Xiao L, Tan LM, Xiao D, Chen YX, Li X, et al: Association between well-characterized lung cancer lncRNA polymorphisms and platinum-based chemotherapy toxicity in Chinese patients with lung cancer. Acta Pharmacol Sin 38: 581-590, 2017.

25. Zhao T, Jin F, Li J, Xu Y, Dong H, Liu Q, Xing P, Zhu G, Xu H and Miao Z: Dietary isoflavones or isoflavone-rich food intake and breast cancer risk: A meta-analysis of prospective cohort studies. Clin Nutr 38: 136-145, 2019.

26. Tse G and Eslick GD: Soy and isoflavone consumption and risk of gastrointestinal cancer: A systematic review and meta-analysis. Eur J Nutr 55: 63-73, 2016.

27. Wada K, Tsuji M, Tamura T, Konishi K, Kawachi T, Hori A, Tanabashi S, Matsushita S, Tokimitsu N and Nagata C: Soy isoflavone intake and stomach cancer risk in Japan: From the Takayama study. Int J Cancer 137: 885-892, 2015.

28. Zaheer K and Humayoun AM: An updated review of dietary isoflavones: Nutrition, processing, bioavailability and impacts on human health. Crit Rev Food Sci Nutr 57: 1280-1293, 2017

29. Applegate C, Rowles J, Ranard K, Jeon S and Erdman J: Soy consumption and the risk of prostate cancer: An updated systematic review and meta-analysis. Nutrients 10: 40, 2018.

30. Woo HD and Kim J: Dietary flavonoid intake and risk of stomach and colorectal cancer. World J Gastroentero 19: 1011-1019, 2013.

31. Nachvak SM, Moradi S, Anjom-Shoae J, Rahmani J, Nasiri M, Maleki V and Sadeghi O: Soy, soy isoflavones, and protein intake in relation to mortality from all causes, cancers, and cardiovascular diseases: A systematic review and dose-response meta-analysis of prospective cohort studies. J Acad Nutr Diet 119 $1483-1500,2019$.

32. Khan N and Mukhtar H: Dietary agents for prevention and treatment of lung cancer. Cancer Lett 359: 155-164, 2015.

33. Pan W: A comparative review of statistical methods for discovering differentially expressed genes in replicated microarray experiments. Bioinformatics 18: 546-554, 2002.

34. Hu Z, Fan C, Oh DS, Marron JS, He X, Qaqish BF, Livasy C, Carey LA, Reynolds E, Dressler L, et al: The molecular portraits of breast tumors are conserved across microarray platforms. BMC Genomics 7: 96, 2006.

35. Fu X, Ravindranath L, Tran N, Petrovics G and Srivastava S Regulation of apoptosis by a prostate-specific and prostate cancer-associated noncoding gene, PCGEM1. DNA Cell Biol 25: 135-141, 2006.

36. Iyer MK, Niknafs YS, Malik R, Singhal U, Sahu A, Hosono Y, Barrette TR, Prensner JR, Evans JR, Zhao S, et al: The landscape of long noncoding RNAs in the human transcriptome. Nat Genet 47: 199-208, 2015.

37. Gupta RA, Shah N, Wang KC, Kim J, Horlings HM, Wong DJ, Tsai M, Hung T, Argani P, Rinn JL, et al: Long non-coding RNA HOTAIR reprograms chromatin state to promote cancer metastasis. Nature 464: 1071-1076, 2010.

38. Xue X, Yang YA, Zhang A, Fong K, Kim J, Song B, Li S, Zhao JC and Yu J: LncRNA HOTAIR enhances ER signaling and confers tamoxifen resistance in breast cancer. Oncogene 35: 2746-2755, 2016

39. Kazemzadeh M, Safaralizadeh R and Orang AV: LncRNAs: Emerging players in gene regulation and disease pathogenesis. J Genet 94: 771-784, 2015.

40. Zhang X, Liang W, Liu J, Zang X, Gu J, Pan L, Shi H, Fu M, Huang Z, Zhang Y, et al: Long non-coding RNA UFC1 promotes gastric cancer progression by regulating miR-498/Lin28b. J Exp Clin Cancer Res 37: 134, 2018.

41. Chi Y, Wang D, Wang J, Yu W and Yang J: Long non-coding RNA in the pathogenesis of cancers. Cells 8: 1015, 2019.
42. Chen R, Li WX, Sun Y, Duan Y, Li Q, Zhang AX, Hu JL, Wang YM and Gao YD: Comprehensive analysis of lncRNA and mRNA expression profiles in lung cancer. Clin Lab 63: 313-320, 2017.

43. Wei MM and Zhou GB: Long non-coding RNAs and their roles in non-small-cell lung cancer. Genomics Proteomics Bioinformatics 14: 280-288, 2016.

44. Han Q, Lin X, Zhang X, Jiang G, Zhang Y, Miao Y, Rong X, Zheng X, Han Y, Han X, et al: WWC3 regulates the Wnt and Hippo pathways via dishevelled proteins and large tumour suppressor 1, to suppress lung cancer invasion and metastasis. J Pathol 242: 435-447, 2017

45. Shao L, Li H, Chen J, Song H, Zhang Y, Wu F, Wang W, Zhang W, Wang F, Li H and Tang D: Irisin suppresses the migration, proliferation, and invasion of lung cancer cells via inhibition of epithelial-to-mesenchymal transition. Biochem Biophys Res Commun 485: 598-605, 2017

46. Bai X, Meng L, Sun H,Li Z,Zhang X and Hua S: MicroRNA-196b inhibits cell growth and metastasis of lung cancer cells by targeting Runx2. Cell Physiol Biochem 43: 757-767, 2017.

47. Liu G, Pei F, Yang F, Li L, Amin AD, Liu S, Buchan JR and Cho WC: Role of autophagy and apoptosis in non-small-cell lung cancer. Int J Mol Sci 18: 367, 2017.

48. Gan PP, Zhou YY, Zhong MZ, Peng Y, Li L and Li JH: Endoplasmic reticulum stress promotes autophagy and apoptosis and reduces chemotherapy resistance in mutant p53 lung cancer cells. Cell Physiol Biochem 44: 133-151, 2017.

49. Xu J, Su C, Zhao F, Tao J, Hu D, Shi A, Pan J and Zhang Y: Paclitaxel promotes lung cancer cell apoptosis via MEG3-P53 pathway activation. Biochem Biophys Res Commun 504: 123-128, 2018

50. Liu YH, Liu GH, Mei JJ and Wang J: The preventive effects of hyperoside on lung cancer in vitro by inducing apoptosis and inhibiting proliferation through Caspase- 3 and P53 signaling pathway. Biomed Pharmacother 83: 381-391, 2016.

51. Goldar S, Khaniani MS, Derakhshan SM and Baradaran B: Molecular mechanisms of apoptosis and roles in cancer development and treatment. Asian Pac J Cancer Prev 16: 2129-2144, 2015.

52. Zhang Y, Li Q, Wei S, Sun J, Zhang X, He L, Zhang L, Xu Z and Chen D: ZNF143 suppresses cell apoptosis and promotes proliferation in gastric cancer via ROS/p53 axis. Dis Markers 2020: $5863178,2020$.

53. Gupta A, Behl T, Heer HR, Deshmukh R and Sharma PL: Mdm2-P53 interaction inhibitor with cisplatin enhances apoptosis in colon and prostate cancer cells in-vitro. Asian Pac J Cancer Prev 20: 3341-3351, 2019.

54. Ellis HM and Horvitz HR: Genetic control of programmed cell death in the nematode C. elegans. Cell 44: 817-829, 1986

55. Sarfstein R, Nagaraj K, LeRoith D and Werner H: Differential effects of insulin and IGF1 receptors on ERK and AKT subcellular distribution in breast cancer cells. Cells 8: 1499, 2019.

56. Ma JB, Bai JY, Zhang HB, Jia J, Shi Q, Yang C, Wang X, He D and Guo P: KLF5 inhibits STAT3 activity and tumor metastasis in prostate cancer by suppressing IGF1 transcription cooperatively with HDAC1. Cell Death Dis 11: 466, 2020.

57. Hu J, Liu X, Chi J, Che K, Feng Y, Zhao S, Wang Z and Wang Y: Expressions of IGF-1, ERK, GLUT4, IRS-1 in metabolic syndrome complicated with colorectal cancer and their associations with the clinical characteristics of CRC. Cancer Biomark 21: 883-891, 2018

58. Wang YA, Sun Y, Palmer J, Solomides C, Huang LC, Shyr Y, Dicker AP and Lu B: IGFBP3 modulates lung tumorigenesis and cell growth through IGF1 signaling. Mol Cancer Res 15: 896-904, 2017.

59. Furstenberger $\mathrm{G}$ and Senn HJ: Insulin-like growth factors and cancer. Lancet Oncol 3: 298-302, 2002.

60. Zhang H, Zhang C and Wu D: Activation of insulin-like growth factor 1 receptor regulates the radiation-induced lung cancer cell apoptosis. Immunobiology 220: 1136-1140, 2015.

61. Brambilla E, Gazzeri S, Gouyer V and Brambilla C: Mechanisms of lung oncogenesis. Rev Prat 43: 807-814, 1993 (In French).

62. Wang LJ, Li QJ, Le Y, Ouyang HY, He MK, Yu ZS, Zhang YF and Shi M: Prognostic significance of sodium-potassium ATPase regulator, FXYD3, in human hepatocellular carcinoma. Oncol Lett 15: 3024-3030, 2018

63. Velloso FJ, Bianco AF, Farias JO, Torres NE, Ferruzo PY, Anschau V, Jesus-Ferreira HC, Chang TH, Sogayar MC, Zerbini LF and Correa RG: The crossroads of breast cancer progression: Insights into the modulation of major signaling pathways. Onco Targets Ther 10: 5491-5524, 2017. 
64. Chuang $\mathrm{CH}$, Cheng TC, Leu YL, Chuang KH, Tzou SC and Chen CS: Discovery of Akt kinase inhibitors through structure-based virtual screening and their evaluation as potential anticancer agents. Int J Mol Sci 16: 3202-3212, 2015.

65. Datta SR, Brunet A and Greenberg ME: Cellular survival: A play in three Akts. Genes Dev 13: 2905-2927, 1999.

66. Yu X, Yuan Y, Zhi X, Teng B, Chen X, Huang Q, Chen Y, Guan Z and Zhang Y: Correlation between the protein expression of A-kinase anchor protein 95, cyclin D3 and AKT and pathological indicators in lung cancer tissues. Exp Ther Med 10: 1175-1181, 2015

67. Kim BM, Kim DH, Park JH, Surh YJ and Na HK: Ginsenoside $\mathrm{Rg} 3$ inhibits constitutive activation of NF-kB signaling in human breast cancer (MDA-MB-231) cells: ERK and akt as potential upstream targets. J Cancer Prev 19: 23-30, 2014.

68. Bellacosa A, Testa JR, Moore R and Larue L: A portrait of AKT kinases: Human cancer and animal models depict a family with strong individualities. Cancer Biol Ther 3: 268-275, 2004.
69. Cheng JQ, Lindsley CW, Cheng GZ, Yang H and Nicosia SV: The Akt/PKB pathway: Molecular target for cancer drug discovery. Oncogene 24: 7482-7492, 2005.

70. Hirsch T, Marzo I and Kroemer G: Role of the mitochondrial permeability transition pore in apoptosis. Biosci Rep 17: 67-76, 1997.

71. Koo J, Cabarcas-Petroski S, Petrie JL, Diette N, White RJ and Schramm L: Induction of proto-oncogene BRF2 in breast cancer cells by the dietary soybean isoflavone daidzein. BMC Cancer 15: 905, 2015.

72. Guo S, Wang Y, Li Y, Li Y, Feng C and Li Z: Daidzein-rich isoflavones aglycone inhibits lung cancer growth through inhibition of NF-kB signaling pathway. Immunol Lett 222: 67-72, 2020.

This work is licensed under a Creative Commons Attribution-NonCommercial-NoDerivatives 4.0 International (CC BY-NC-ND 4.0) License. 